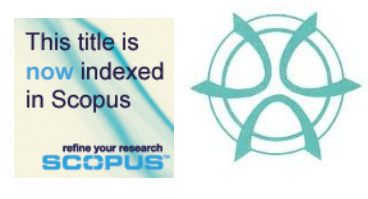

PLANNING MALAYSIA:

Urban Planning and Local Governance

Volume III (2014), Page 1 - 14

\title{
GEOSPATIAL TECHNOLOGY APPROACHES IN URBAN MORPHOLOGY FOR RESILIENT URBAN GOVERNANCE
}

\section{Norzailawati binti Mohd Noor ${ }^{1}$, Marina Mohd Nor ${ }^{2}$, Alias Abdullah ${ }^{3}$ and Rustam Khairi Zahari ${ }^{4}$}

\author{
${ }^{1,2,3 \& 4}$ Kulliyyah of Architecture and Environmental Design \\ INTERNATIONAL ISLAMIC UNIVERSITY MALAYSIA
}

\begin{abstract}
This study analysed the potential of applications of geospatial technology in urban planning research in urban morphology. Urban morphology is the study of the form of human settlements and the process of their formation and transformation. It is an approach in designing urban form that considers both physical and spatial components of the urban structure. This study was conducted in Georgetown, Penang with the main purpose to identify the evolution of urban morphology and the land use expansion using remote sensing images and Geographical Information System (GIS) technique. Four series of temporal satellite SPOT 5 J from 2004, 2007, 2009, and 2014 were used to detect an expansion of land use development using change detection technique. Three types of land use were identified, namely built-up area, unbuilt-up area, and water bodies with a good accuracy of above $85 \%$. The result showed that the built-up area significantly increased due to the rapid development in urban area. Finally, the result provided an understanding and strengthened the relationship between urban planning and geospatial applications in creating sustainable and resilient city and future urban governance.
\end{abstract}

Keyword: Urban morphology, GIS, Remote sensing, urban planning, urban governance

${ }^{1}$ Assistant Professor at Department of Urban and Regional Planning. Email: norzailawati@gmail.com

${ }^{2}$ Postgraduate student at Department of Urban and Regional Planning. Email: marina.mn@ gmx.com

${ }^{3}$ Professor at Department of Urban and Regional Planning. Email: dralias@iium.edu.my

${ }^{4}$ Assistant Professor at the Department of Urban and Regional Planning. Email: rustam@iium.edu.my 
Norzailawati binti Mohd Noor, Marina Mohd Nor, Alias Abdullah and Rustam Khairi Zahari

Evaluating the Geospatial Technology Approaches in Urban Morphology for Resilient Urban Governance

\section{INTRODUCTION}

Approximately half of the world population is living in urbanised area, and that number is about to rise in the next decade. Therefore, improving our knowledge on urban pattern and its dynamics at multiple spatial scales is a real challenge for research especially in achieving resilience in urban governance. The understanding of urban growth and interpretation of urban morphology can be a key challenge to the rapid urbanisation of the settlements (Cheng, 2011). Urban morphology is an approach in designing urban form that considers both physical and spatial components of the urban structure (Bentley \& Butina, 1990; Paul, 2008). The criteria for evolutionary process of development at a particular city, such as plots, blocks, street layout, buildings, urban material, and open spaces, are considered as part of the history.

From the view of classic concepts that develop by M.R.G Conzen which known as pioneer in urban morphology, he divided urban form into three part which are first, town plan, secondly is building fabric and thirdly is land and building utilization (Whitehand,2007). This concept have become important as a process of urban development and provide an understanding on urban morphology Moreover, urban morphology can change over time as new urban fabric is added and as the existing fabric is internally modified. The changes of internal components are major concerns that represent the interrelation of physical evolution such as economic, cultural, and political dimensions that are associated with urban dynamics (Rashed et al., 2005).

The urban morphology analysis can be performed by using geographic information system (GIS) and remote sensing technique. These techniques can reveal the relationships among patterns, trends, forms, and structures of urban settlements. These techniques also help investigate the past and present patterns and trends of urban growth. Morphological analysis makes it possible to summarise the changes and trends of urban spatial structure and urban form. As a result, urban morphology analysis requires multitemporal datasets covering the whole urban area across a long period. Stimulated by rapid advances in geospatial technologies, highresolution remotely sensed imagery has become widely available and at a low cost. These advances have made monitoring urban growth possible, and the availability of multiple temporal datasets has very much been improved recently (Liu \& Zhou 2005, Xian \& Crane 2005). Multitemporal analysis is a kind of spatial analysis and model using multitemporal datasets. 
Liu and Zhou (2005) report a land use change trajectory analysis method based on multitemporal imagery, and further apply this method for the prediction of urban growth into the future.

Satellite imagery with different spatial resolutions is a real opportunity and is a very relevant data source in this domain. Remote sensing is widely known among urban planners, city planners, and policy makers as a useful tool for extracting biophysical information about urban environment including land cover and land use mapping, urban morphology description and analysis, vegetation distribution and characterisation, hydrography, and disaster relief. This tool is also widely used in the field of natural resource exploration and management. However, little is known about the detection of the subtle relationships between physical appearance of urban landscape and socioeconomic conditions of the population. The data that are currently available from Earth observation systems present an opportunity to collect information about urban settlements at several scales and on several dimensions (Netzband \& Jürgens, 2010, chap. 1), and urban population growth and problems will increase in relevance in the coming decades (Sembler, 2006; Stow et al., 2007; Weeks, Getis, Hill, Gadalla, \& Rashed, 2004). Therefore, it is important to demonstrate how remote sensing tools can contribute useful information to the study of cities and urban settlements. In this context, the objective of this study was to analyse an urban morphology based on urban pattern using integration of remote sensing satellite and GIS techniques in achieving resilience in urban planning governance. This study was performed on an urban area of Georgetown for calibration of feature selection and classification.

\section{STUDY AREA}

The study was conducted in Georgetown, a historic city in the state of Penang. Comprises Penang Island and Georgetown, Penang is the heart of the metropolitan area, which is the second largest urban conurbation in Malaysia. The city of Georgetown was established in 1786 by the British and it is the first British port town along the Straits of Malacca. The city has more than 200 years of urban history. In this study, the urban morphology of Georgetown was analysed to understand the trends and patterns of urban form and the expansion of urban growth. The increasing intervention from high rise construction and new developments within the historic urban fabric has given some transformation and evolution in urban morphology of the city (Shuhana et al., 2012). 
Norzailawati binti Mohd Noor, Marina Mohd Nor, Alias Abdullah and Rustam Khairi Zahari

Evaluating the Geospatial Technology Approaches in Urban Morphology for Resilient Urban Governance

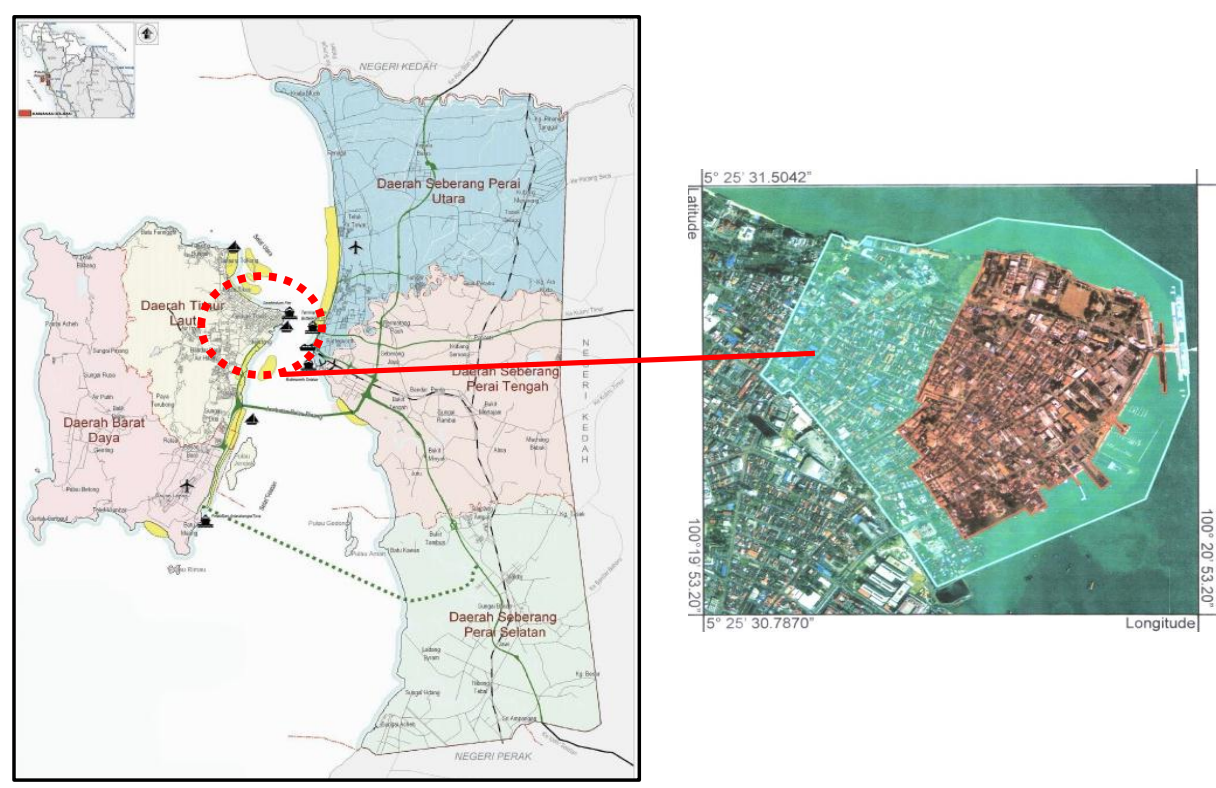

Figure 1: Key plan Georgetown in Pulau Pinang context (left) and study area (right) (Source: Structure Plan Pulau Pinang 2020 \& Draft Special Area Plan Georgetown 2011)

\section{URBAN MORPHOLOGY FOR RESILIENCE URBAN GOVERNANCE}

Urban morphology refers to the form of human settlements and the process of their formation and transformation. This morphology occurs based on certain characteristics such as urban fabrics, natural and man-made structures, street layout, architectural complexity, urban materials, and human activities (Sharifah et al., 2013). These characteristics influence the changes in environment, economy, and social activities of the urban settlement. Besides that, urban morphology analysis can help identify the transformation of urban form development and the evolutionary of urban form and structure (Cheng, 2011).

Moreover, urban morphology plays a fundamental role in the resilience of urban system. In recent years, the challenge facing most of urban areas is how to accommodate future population and development growth in a sustainable manner. Any of transformation in urban patterns and forms should be taken seriously so that it will minimise the negative impacts 
towards the environment. In some countries such as Granada, the environment of the city becomes physically degraded, damaged, or even destroyed by the impact of the urban development that follows modernisation. The main issues on urban morphology and planning are still poorly developed.

Thus, the significance of urban morphological study has yet to be realised amongst urbanists (Whitehand, 2004). Therefore, urban morphology study provides important knowledge to the planner in order to develop any area in a city or even for fringe belt. Lack of interest and awareness in history among the planners and others have prevented them from developing the settlements with systematic urban dynamics. Hence, the responsibility for the built environment is not taken seriously towards realisation of sustainable urban development. Therefore, urban planners need information to allow them to respond to the expectations and needs of the urban growth. The information can help forecast future model of urban settlements (Kalyani \& Govindarajulu, 2013).

Urban morphology study can help in design control through policy. Due to deficiency in policy for design control, urban morphology study can be an important issue and can be considered in developing a method for expressing detailed design policies (Hall, 1997). The phenomenon of urban morphology on urban system can affect the economy, environment, climate, technology, and others of the entire city or even region. This urban morphology process can be a force that drives demand and change in the policies or strategies in order to shape sustainable and resilient urban form and structure. From this process, all agencies involved in city planning can structure the urban form into a systematic arrangement (Gillen, 2006).

Understanding the urban morphology in selected area helps decision makers identify the strong or potential asset in the area. In the context of this study, Georgetown is known as a heritage area due to numerous heritage buildings and living cultures. Public agencies and the local authority have taken initiatives to market this city's image to the world. These initiatives give benefit to the city's strategic planning and marketing, and give satisfaction and pride to the citizens (Ismail \& Mohd-Ali, 2006). Besides that, culture diversity in Georgetown has a great contribution towards the morphology of the urban area. By having many cultures in the city, the government could play a role in implementing cultural policies to produce great urban transformation (Pereira \& Nofre, 2011). Thus, the locals and international tourists would understand the morphology of different cultures in Georgetown that has been established since the ancient years. 
Norzailawati binti Mohd Noor, Marina Mohd Nor, Alias Abdullah and Rustam Khairi Zahari

Evaluating the Geospatial Technology Approaches in Urban Morphology for Resilient Urban Governance

There is historic and cultural significance worth of preservation for sustainable development in Georgetown. However, uncontrolled development has resulted in the building of new buildings and facades with old buildings sandwiched in between them. Therefore, initiatives should be taken to give life back to the historic city of Georgetown and to regenerate the area. Hence, guidelines and policies on urban conservation must be taken seriously by all parties such as the local authorities, Federal and State Governments, Department of Museums Malaysia, heritage trusts, and other professional bodies (Shahrul et al., 2013).

\section{MATERIALS AND METHOD}

\section{Data and Ancillary Information}

Data were collected from primary and secondary sources (see Table 1) such as maps and satellite imagery. Land use map of Georgetown and satellite images from Spot $5 \mathrm{~J}$ were used in this study. For Spot $5 \mathrm{~J}$, four satellite images (nominally 2004, 2007, 2009, and 2014) were used in order to identify land cover changes in the study area.

Table 1: Materials and data used in this study.

\begin{tabular}{|c|c|c|c|c|}
\hline Data Types & Year & Provider & Process & Output \\
\hline \multicolumn{5}{|c|}{ Maps } \\
\hline $\begin{array}{l}\text { Land use map } \\
\text { of } \\
\text { Georgetwon }\end{array}$ & 2013 & $\begin{array}{c}\text { Jabatan } \\
\text { Perancang } \\
\text { Bandar \& Desa } \\
\text { (JPBD) }\end{array}$ & $\begin{array}{l}\text { Digitize, } \\
\text { coordinates }\end{array}$ & $\begin{array}{c}\text { Map of Georgetown } \\
2013\end{array}$ \\
\hline \multicolumn{5}{|c|}{ Satellite Images } \\
\hline Spot $5 \mathrm{~J}$ & $\begin{array}{c}2004,2007,2 \\
009,2014\end{array}$ & $\begin{array}{c}\text { Agensi Remote } \\
\text { Sensing Malaysia } \\
\text { (ARSM) }\end{array}$ & $\begin{array}{l}\text { Geometric } \\
\text { correction, } \\
\text { Enhancement, } \\
\text { Classification }\end{array}$ & $\begin{array}{l}\text { Land use and land } \\
\text { cover map } \\
2004,2007,2009 \& \\
2014\end{array}$ \\
\hline
\end{tabular}

\section{Methods}

In order to understand the dynamic phenomenon of urban morphology, the basic requirements are information on land use change, urban pattern identification, and computation of change detection. In this study, all this required information was compiled and converted to digital forms, and was readily used in both data processing in Digital Image Processing system and Geographic Information System. Two main Digital Image Processing 
systems namely ERDAS Imagine and Envi were used in this study. ArcGIS software as the Geographic

Information System was also used to generate various thematic layers consisting of Georgetown's administrative boundaries, roads, contours, and administrative boundary map, using urban maps and other available maps. Overall, five scenes from Spot $5 \mathrm{~J}$ were used to analyse the land use change between 2004 and 2014. For all images, there were free clouds. Preprocessing was used to comprise a series of sequential operations including atmospheric correction or normalisation, image registration, geometric correction, and masking (e.g., for clouds, water, irrelevant features).

Change detection is the process of identifying differences of a feature or phenomenon in the state by observing the feature or phenomenon at different times. In remote sensing, it is useful in land use or land cover change analysis such as in urban morphology. In this study, the analysis of change detection was carried out. The analysis was used to identify the changes of land cover from 2004 to 2014. Using image differencing involves the subtraction of two images and the addition of a constant value to the result. The analysis of change detection develops an image differencing algorithm as the function, and creates a change detection image as an output. Thus, in this study, from the images, the expansion of the land use and land cover within 11 years was detected. The images were then classified into three namely built-up area, unbuilt-up area, and water bodies in GIS software of ARCGIS 10. The images were also assigned with different colour to differentiate the class to analyse the changes of land use respectively.

\section{RESULTS AND DISCUSSION}

Four images obtained from 2004 to 2014 were classified using supervised classification. The images were classified into three classes namely built up area, unbuilt-up area, and water bodies to identify the expansion of land use. The assessment of the classification was carried out based on the classified image in each processing. Table 2 below summarises the accuracy of the assessment of the classification process for each satellite image. An overall classification accuracy of over $85 \%$ was achieved during image processing. 
Norzailawati binti Mohd Noor, Marina Mohd Nor, Alias Abdullah and Rustam Khairi Zahari

Evaluating the Geospatial Technology Approaches in Urban Morphology for Resilient Urban Governance

Table 2: Accuracy Assessment for land use classification for the images

\begin{tabular}{cccc}
\hline Satellite Images & Year & Accuracy (\%) & Kappa Statistic \\
\hline & 2004 & 95.00 & 0.9208 \\
Spot 5 J & 2007 & 95.00 & 0.9200 \\
& 2009 & 93.68 & 0.8998 \\
\hline & 2014 & 98.67 & 0.9776 \\
\hline
\end{tabular}

Expansion of Land use (2004-2014)

The expansion of land use can be seen from 2004 until 2014. The images clearly showed that the urban development significantly increased. The expansion of the urban area was mostly towards the Strait of Malacca. The images showed that the town expanded inwards and there was also a series of reclamation extending towards Weld Quay as the new waterfront. Due to rapid changes in Georgetown, unbuilt-up area decreased, thus leading to an increase in the built up area with the increasing intervention from high rise construction and new developments within the historic urban fabric. Hence, these changes brought some transformation and evolution in urban morphology of the city (Shuhana et al., 2012). Figure 3 shows the development of land use in Georgetown.

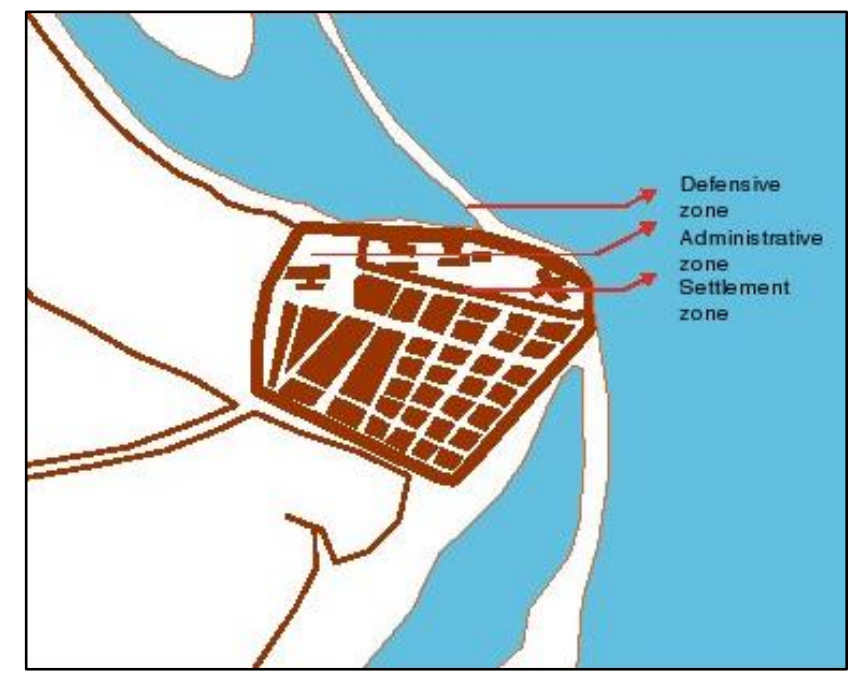

Figure 2: Temporal land use classification in Study Area obtained from SPOT J imageries 
In Georgetown city, we can see the changes in urban morphology components namely building plots, street layout and open spaces. For the building plots, there are only three zone that invented by British authority which are defence zone, administrative zone and settlement zone.

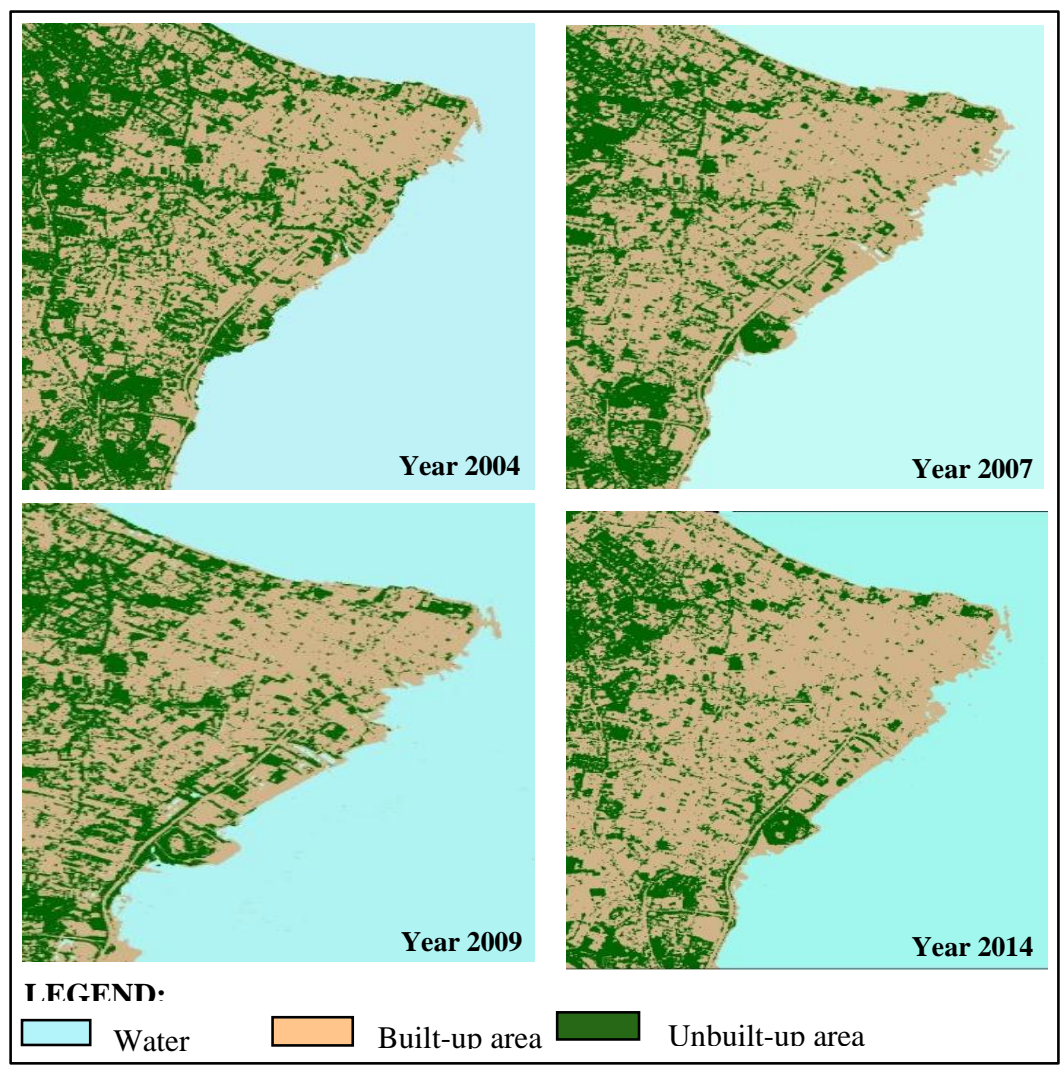

Figure 3: The earliest settlement of Georgetown with the implementation of unplanned gridiron concept.

(Source: Hassan, 2009)

Due to the development of Georgetown, building plots were increased in order to support the population of people that influx in this city. This lead to the foundation of the street settlement and layout. Every street layout represents different settlement from different religions and ethnicity. The direction of expansion land use or the encroachment of land use were inwards to the inner city of Georgetown and the building plots become more complex when the trading activities become successful. 
Norzailawati binti Mohd Noor, Marina Mohd Nor, Alias Abdullah and Rustam Khairi Zahari

Evaluating the Geospatial Technology Approaches in Urban Morphology for Resilient Urban Governance

Moreover, the street layout can be categorized according to the background of the people that living in the street. The zones are as below and shown in Figure 4:

1. Zone 1: Indian Muslim Settlement

2. Zone 2: Chinese Settlement

3. Zone 3: Malay Settlement

4. Zone 4: Indian Hindu Settlement

5. Zone 5: Commercial Area

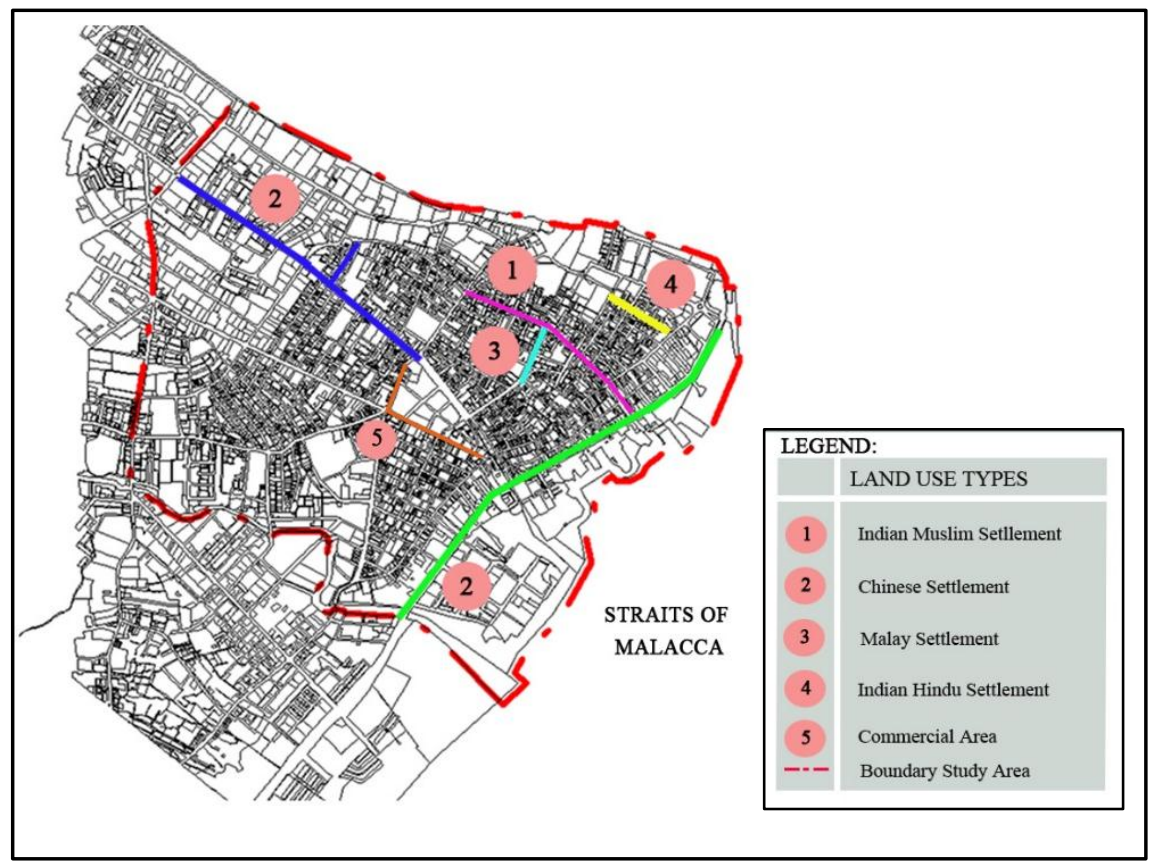

Figure 4: Distribution of street layout settelment

Only religions and ethnicity background can only be traced based on the people around the street, types of shop, types of goods sold and architecture buildings during site observation.

Burke and Ewan (1999) stated that open space contributes the quality of life to the people. Thus, there are four area that served as open space for public in this study area which are: 
1. Esplanade

2. Taman Kota Lama

3. Taman Penyayang

4. Padang Brown

During British colonial, Esplanade was the first colonial open space in the city. The esplanade is associated with the Fort Cornwallis and adjacent to the colonial government buildings. The activities occur at Taman Kota Lama and Esplanade significantly contributes to the visual and sensory experience of Georgetown's townscape.

However, in study area, there are only four open spaces that can be access by public. Therefore, the development of Georgetown city is not well balanced with the existing of open spaces. With the minimum numbers of open spaces, it will give negative impact to the community in order to have social interaction with others people. It would give problems to people to travel far from their home for only to do recreational activity.

\section{CONCLUSION}

In this study, the process of development occurring in the metropolitan area, city, town, or village was examined. The study gave basic understanding on how the settlements faced the evolution of development in terms of urban forms and urban spatial structure. Moreover, traditional urban theories investigate how cities develop and grow through systematic interactions of infrastructure, people, and economic activities. With given advances in technology and the sheer scale and pace of contemporary urban growth, the most rapid changes in urban form, pattern, and structure are taking place where historical roots are weakest as in the recent suburbs of long established Western cities, or in the new cities of developing countries. That is how the significance of urban morphology replaces or improves the weakest area to become a more urban dynamic area. The advancement of geospatial technology in studying the urban morphology such as GIS and remote sensing shows that it will help in dealing with spatial problems such as urban planning and management issues. The technology is useful in assisting planners, decision makers, and the community to efficiently respond to challenges, plan successful future, and improve service delivery (Narimah, 2006). In short, GIS and remote sensing should play more roles in managing, monitoring, and planning land use development in Malaysia. This study could give many parties such as planner, architect, and local authority 
Norzailawati binti Mohd Noor, Marina Mohd Nor, Alias Abdullah and Rustam Khairi Zahari

Evaluating the Geospatial Technology Approaches in Urban Morphology for Resilient Urban Governance

an incredible capability in decision making processes such as planning, policy making, and legislating law.

\section{ACKNOWLEDGEMENT}

The authors greatly acknowledge the Malaysian Remote Sensing Agency, Majlis Perbandaran Pulau Pinang and Town and Urban Planning Department and Malaysian Remote Sensing Agency for providing invaluable respective data used in this study. Authors sincerely thank all referees for their suggestions to improve the manuscript.

\section{REFERENCES}

Allan, P., Bryant, M., Wirsching, C., Garcia, D., \& Teresa Rodriguez, M. (2013). The Influence of Urban Morphology on the Resilience of Cities Following an Earthquake. Journal of Urban Design, 18(2), 242-262.

Bagan, H., \& Yamagata, Y. (2012). Landsat analysis of urban growth: How Tokyo became the world's largest megacity during the last 40years. Remote Sensing of Environment, 127, 210-222.

Bentley, I. \& Butina, G. (1990), in Gleave, S. [ed.], Urban design, Architects Journal, October 24, v.192, no.17, pp.61-71.

Burke, J \& Ewan, J.(199). Sonoran Preserve Master Plan for the Phoenix Sonoran Dessert. City of Phoenix Parks, Recreational Library Department: Arizona.

Cheng, J. (2011). Exploring urban morphology using multi-temporal urban growth data: a case study of Wuhan, China. Asian Geographer, 28(2), $85-103$.

Draft Special Area Plan Georgetown. (2011). Jabatan Perancang Bandar \& Desa Pulau Pinang.

Gospodini, A. (2004). Urban morphology and place identity in European cities: built heritage and innovative design. Journal of Urban Design, 9(2), $225-248$.

Gillen, M. (2006). The challenge of attaining a sustainable urban morphology for South East Queensland. Planning Practice and Research, 21(3), 291-308.

Hall, a. C. (1997). Dealing with incremental change: An application of urban morphology to design control. Journal of Urban Design, 2(3), 221-239.

Hassan, A. S. (2009). The British colonial 'divide and rule' concept: its influence to transport access in inner city of George Town, Penang. Transportation , 36 (3), 309 - 324. 
Ismail, S., \& Mohd-Ali, N. A. (2011). The Imaging of Heritage Conservation in Historic City of George Town for City Marketing. Procedia Engineering, 20, 339-345.

Jiang, H., \& Eastman, J. R. (2000). Application of fuzzy measures in multicriteria evaluation in GIS. International Journal of Geographical Information Science, 14(2), 173-184.

Kalyani, P. (2013). A multi-scale Urban Analysis Using Remote Sensing and GIS, (3), 1-11.

Kuffer, M., \& Barrosb, J. (2011). Urban Morphology of Unplanned Settlements: The Use of Spatial Metrics in VHR Remotely Sensed Images. Procedia Environmental Sciences, 7, 152-157.

Moudon, A.V. (1997). Urban Morphology as An Emerging Interdisciplinary Field. International Seminar on Urban Form, 1, 3-10.

Netzband, M., \& Jurgens, C. (2010). Urban and suburban areas as a research topic for remote sensing. In T. Rashed \& C. Jurgens (Eds.), Remote sensing of urban and suburban areas (pp. 1-9). Netherlands, Dordrecht: Springer.

Ng, E., Yuan, C., Chen, L., Ren, C., \& Fung, J. C. H. (2011). Improving the wind environment in high-density cities by understanding urban morphology and surface roughness: A study in Hong Kong. Landscape and Urban Planning, 101(1), 59-74.

Paul, S., \& Congress, J. (2008). QUT Digital Repository: Presenting The Past : The Impact Of Urban Morphology In Shaping The Form Of The City.

Pereira, P. (2011). Rebuilding urban morphology: new centralities and urban inequalities in Southern European cities, 655-684.

Peeters, A., \& Etzion, Y. (2012). Automated recognition of urban objects for morphological urban analysis. Computers, Environment and Urban Systems, 36(6), 573-582.

Rashed, T.,Weeks, J. R., Stow, D., \& Fugate, D. (2005). Measuring Temporal Compositions Of Urban Morphology Through Spectral Mixture Analysis : Toward A Soft Approach To Change Analysis.

Robinson, D. (2006). Urban morphology and indicators of radiation availability. Solar Energy, 80(12), 1643-1648.

Narimah,S. (2006). Applications of Geographic Information Systems in Urban Land Use Planning in Malaysia, 2025(May), 1-12.

Sembler, C. (2006). Estratificacion social y clases sociales. Una revision anal1'tica de los sectores medios. Technical report, Naciones Unidas CEPAL, Santiago de Chile.

Shuhana,S., Ahamd, B.S, \& Rohayah, C.A. (2012). Urban Landscape Factors That Influenced the Character of George Town, Penang Unesco World Heritage Site. Procedia - Social and Behavioral Sciences, 50(July), $238-253$. 
Norzailawati binti Mohd Noor, Marina Mohd Nor, Alias Abdullah and Rustam Khairi Zahari

Evaluating the Geospatial Technology Approaches in Urban Morphology for Resilient Urban Governance

Sharifah. K. S. O., Mohamad, N. H. N., \& Abdullah, S. M. S. (2013). The Influence of Urban Landscape Morphology on the Temperature Distribution of Hot-Humid Urban Centre. Procedia - Social and Behavioral Sciences, 85, 356-367.

Said, S. Y., Aksah, H., \& Ismail, E. D. (2013). Heritage Conservation and Regeneration of Historic Areas in Malaysia. Procedia - Social and Behavioral Sciences, 105, 418-428.

Structure Plan Pulau Pinang 2020. (2007). Jabatan Perancang Bandar \& Desa Pulau Pinang.

Weeks, J. R., Getis, A., Hill, A. G., Gadalla, M. S., \& Rashed, T. (2004). The fertility transition in Egypt: Intra-urban patterns in Cairo. Annals of the Association of American Geographers, 94(1), 74-93.

Whitehand, J. W. R., Gu, K., Whitehand, S. M., \& Zhang, J. (2011). Urban morphology and conservation in China. Cities, 28(2), 171-185.

Wilkinson, G.G. (1996). A Review of Current Issues in The Integration of GIS and Remote Sensing Data. International Journal of Geographical Information Systems, 10, 85-101. 